\section{COLOUR AND THE ARGUMENT FROM ILLUSION}

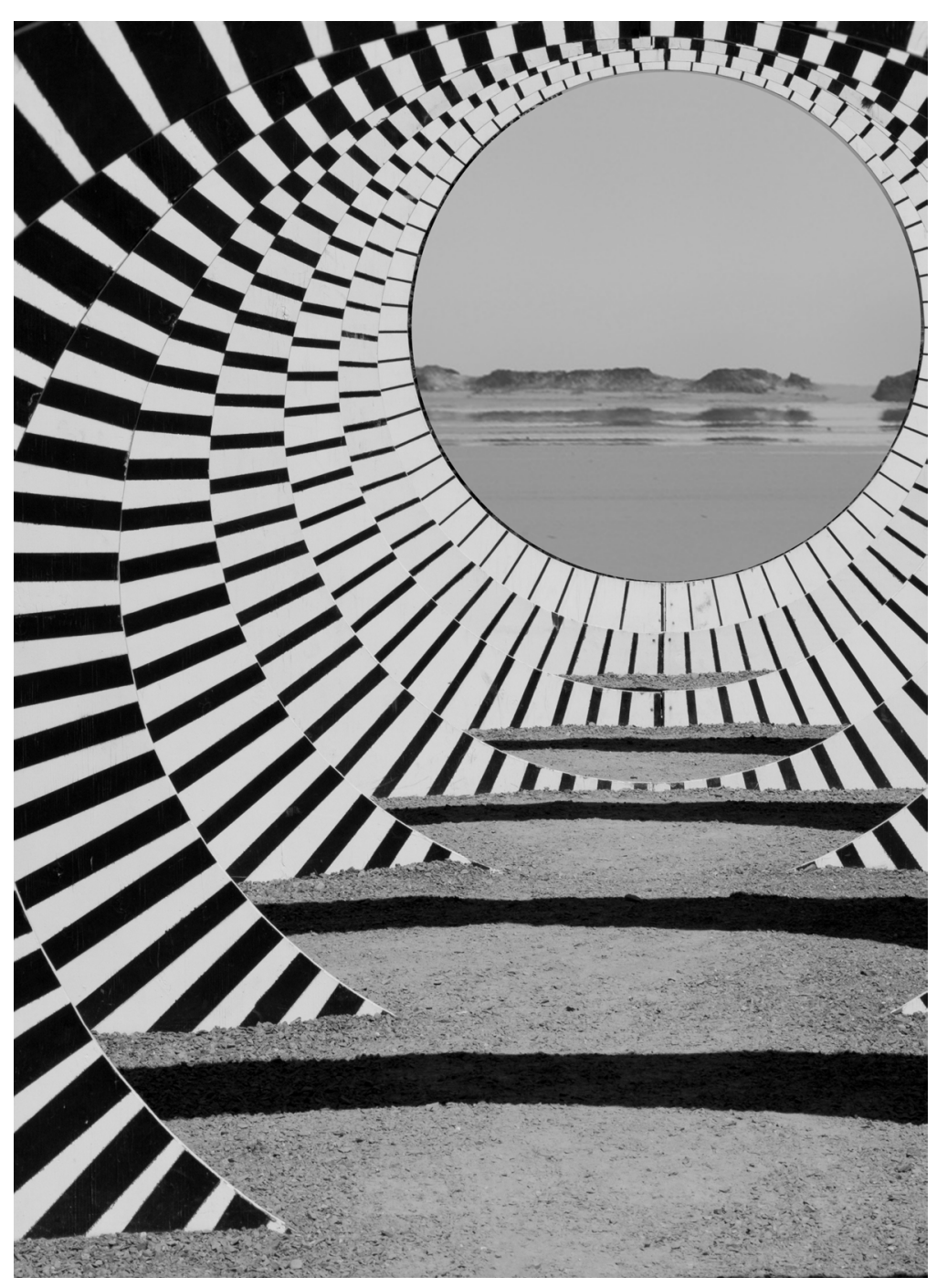

CAMERON YETMAN

\section{ABSTRACT}

For A. J. Ayer, the occurrence of delusions confutes the notion that we perceive the world directly. He argues instead that perceptions are caused by immaterial "sense data" which somehow represent the properties of material things to us in our experiences. J. L. Austin systematically rejects Ayer's claims, arguing that the occurrence of delusions does not preclude the possibility of direct perception, and that, indeed, our normal perception is direct. I challenge both philosophers' ideas by examining how they deal with the phenomenon of colour.

\section{INTRODUCTION}

In "The Argument from Illusion," A. J. Ayer contends that humans have no direct perceptive access to the material world because the appearances of things in that world can be delusive and are, to some extent, causally dependent on the state of the observer. ${ }^{1}$ Instead, perceptions are caused by immaterial "sense-data," which somehow represent the properties of material things to us in our experiences. J. L. Austin systematically rejects Ayer's arguments, concluding that our normal perception of the world is direct. ${ }^{2}$ I propose to challenge both philosophers' ideas by looking at how they deal with the phenomenon of colour. Ultimately, although neither Ayer nor Austin can provide a satisfactory explanation of colour, Austin's theory proves particularly unsatisfactory.

\section{AYER AND ILLUSION}

Ayer introduces the theory of sense-data in terms of the argument from illusion. The argument goes as follows. Sometimes, people have experiences of things which do not exist in the external world. For example, a mirage is an experience with a definite content (it is of something), but it is not caused by a real physical object; there is no oasis. Furthermore, the experience of a mirage is the exact same-Ayer says "qualitatively indistinguishable" - as the experience of an actual oasis off in the distance. ${ }^{3}$ There is simply no way to tell the difference between the two: " $[\mathrm{t}]$ he fact is that from the character of a perception considered by itself ... it is not possible tell whether it is veridical or

\footnotetext{
A. J. Ayer, "The Argument from Illusion," in Introduction to Philosophy: Classical and Contemporary Readings, 2nd ed., ed. John Perry and Michael Bratman (Oxford: Oxford University Press, 1993), 215-18. Ayer does not explicitly agree with this argument in the text, but for ease of wording I will act like he does.

2 J. L. Austin, "A Refutation of the Argument from Illusion," in Introduction to Philosophy: Classical and Contemporary Readings, 2nd ed., ed. John Perry and Michael Bratman (Oxford: Oxford University Press, 1993), 219-27.

3 Ayer, "Argument from Illusion," 217. Ayer provides other examples of this sort, including a straight stick which appears bent underwater and the effect whereby seeing yourself in a mirror looks the same as seeing your twin somewhere behind it.
} 
delusive." $3 y$ "veridical," Ayer is referring to our everyday perceptions of things in the world, which do not seem to deceive or delude us in any way. Few would doubt, for example, that their perception of their morning cup of coffee is somehow misleading; we do believe such perceptions are susceptible to serious skeptical doubt, as we do with mirages. Ayer goes on to argue that because veridical and delusive experiences are often indistinguishable they cannot be caused by completely different things, as one would expect different sorts of causes to have qualitatively different effects. For this reason, it seems absurd to suppose that veridical perceptions are caused by one's direct sensory access to the physical world, while delusive perceptions are caused by incorporeal sense-data. Therefore, because Ayer has already shown that delusions do not depend on the physical facts of the world (there is no mirage, etc.), the material world must only be perceivable through the same means as are delusions (i.e. sense-data).

Perceptions of colour seem to fit well within the framework of sense-data. For Ayer, sense-data serve to give us indirect knowledge of the properties of material things through some "presentative function" which the sense-data hold in relation to those things. ${ }^{5}$ Exactly what this function is or how it works, he admits, is not certain. Colour, as a property of material things, is thus perceived through a mysterious function of sense-data. Additionally, the fact that colour perception relies on the internal state of the observer (shown by the fact that ingesting brain-altering drugs like mescal makes "things appear to change their colours") demonstrates that we do not perceive colour directly (i.e. without mediation). ${ }^{6}$ If we directly perceived colour, it is unclear how a drug could disrupt those perceptions. So, for Ayer, colour is nothing more than the reception of certain informationbearing sense-data into the eyes, which the brain then somehow translates into coloured perceptual experiences. Changing the brain, such as through ingesting certain drugs, thus changes perception.

\section{AUSTIN'S CRITIQUE OF AYER}

Austin criticizes the basic premises of sense-data theory. To begin, he argues that it is not the case, in most of Ayer's examples, that one is having an experience of something which is not really there. For example, Ayer maintains that, in the case of a straight stick halfsubmerged in water, what we see of the submerged section "is not the real quality of a material thing," because the stick is straight and thus cannot also be bent. ${ }^{7}$ In response, Austin retorts, "[w]hat is wrong,

4 Ayer, "Argument from Illusion," 217

5 Ayer, "Argument from Illusion," 215

6 Ayer, "Argument from Illusion," 216.

Ayer, "Argument from Illusion," 216 what is even faintly surprising, in the idea of a stick's being straight but looking bent sometimes?" The fact that a submerged stick looks bent when we know it is straight does not necessitate that the bent part is not real but simply that a stick half-submerged in water looks bent. For Austin, one cannot abstract from the conditions in which the delusion is taking place: the stick looks bent due to the refractive properties of water. But what of mirages? These seem to have no explanation in terms of simple external phenomena. Austin agrees but does not believe this necessitates the introduction of a theory of sense-data, as we already have a name for delusions of this sort: mirages. Furthermore, the person perceiving a mirage is clearly not in a typical state of mind, and so their delusions occur under special circumstances. Indeed, Austin argues that there is no reason to suggest that the existence of occasional delusions - even when they appear identical to normal, non-deluded perceptions - demand there be one common cause for all perceptive experiences,

[f]or even if we make the prior admission (which we have so far found no reason to make) that in the 'abnormal' cases we perceive sense-data we should not be obliged to extend this admission to the 'normal' cases too. For why on earth should it not be the case that, in some few instances, perceiving one sort of thing is exactly like perceiving another? 9

It is simply not evident, for Austin, that two things which appear the same must have the same sort of cause. An analogy could be the trajectory of a baseball: the cause may be a human pitcher, or a pitching machine, but the result is the same either way. We do not generally find this fact even remotely surprising. Likewise, it could well be that we directly perceive the material world and that delusions, if not also directly perceived, have some alternate cause.

It is unclear how Austin will deal with the phenomenon of colour. His only treatment of colour in the text comes on page 225, where he argues that seeing a white wall through blue glasses is not the exact same as seeing a blue wall. His justification for this claim is that, while we may say in either case that the wall "looks blue," the two experiences are very different. ${ }^{10}$ In one, we walk up to a wall in normal conditions, and it looks blue. In the other, we put on strange coloured glasses, and then the wall looks blue. One cannot simply ignore the act of putting on the glasses. What of Ayer's mescal example? Austin would presumably reply that the person under the influence of the drug is in an altered mental state, and so it is no wonder they are having delusive experiences. But what, for Austin, even are delusions? This is really the crux of the problem. For Austin, delusions have two types - those of

8 Austin, "Refutation of Argument from Illusion," 222. Italics mine.

9 Austin, "Refutation of Argument from lllusion," 226.

10 Austin, "Refutation of Argument from Illusion," 225. 
belief and of perception. ${ }^{11}$ Delusions of perception are different from illusions in that they are creations of the mind: “the term 'delusion' does suggest something totally unreal, not really there at all . . delusions are a much more serious matter [than illusions] - something is really wrong, and what's more, wrong with the person who has them." ${ }^{12}$ In a delusion, the mind conjures up something which does not really exist.

\section{CHALLENGING AUSTIN}

Here is my challenge to Austin: if I can show that some part of our everyday perceptive experience is a delusion, it must be the case that direct perception is false. Why is this? Recall that, for Austin, delusions are strange perceptions and sensations conjured up by the mind which have no grounding in everyday experience. Every example he cites of actual delusion - a medical patient seeing pink rats, a person on drugs hallucinating, someone seeing mirages — are examples that only occur in rare and specific circumstances, which we can predict and usually avoid. But what of colour? Experiences of colour are just about as ubiquitous as experiences can get. Surely, if Austin claims that our everyday perception of the world is direct and unmediated by anything like sense-data, perception of colour must be direct and not delusive-right?

Not quite. According to Austin's definition of delusionsomething that is conjured up by the mind-colour perceptions are delusions, and their ubiquity does nothing to mask this fact. The most obvious point to raise in support of the notion that colour is a delusion is the existence of colour-blindness. I may look at an apple and see it as red, while my friend sees the exact same apple as brown. This difference in colour must be manifest either in the apple itself, in our optical instruments, or in our mind's processing of the visual information it receives. In the case of colour-blindness, the colourblind person has certain defective cells in their retina which fail to respond appropriately to certain wavelengths of light. Does this fact nullify the example, because the defect is not in the mind but in the eyes? Well, one could potentially argue that the only reason atypical optical instruments cause atypical perceptions is because they deliver incomplete information to the brain. While this response gives priority back to the brain, assuming its truth without further evidence would be begging the question. As such, one cannot take (as I did for a long time) colour-blindness as the trump card it seems to be.

There are further examples to consider. In 2015, a photograph of a dress was uploaded to the internet which caused widespread debate. ${ }^{13}$

11 Austin does not make this distinction explicit, but it is quite obvious from his discussion on page 220.

12 Austin, "Refutation of Argument from Illusion," 220.

3 Adam Rogers, "The Science of Why No One Agrees on The Colour of This
The issue was that everyone seemed to see its colour differently: some saw blue-and-black, and some white-and-gold. There is a relatively complex neurological explanation for this discrepancy in perception, but the basic explanation is that different people were correcting for chromatic bias in different ways. Chromatic bias is the effect whereby one's brain subtracts the hue of ambient light from one's perceptions to allow for better distinguishing of colours. For instance, when carrying a sheet of printer paper from the bright white light of the outdoors into a room lit with an incandescent bulb, we are not typically shocked that the paper suddenly turns yellow because our brains are correcting for the change in ambient light in such a way that the paper's colour seems consistent; we still think it is white. In an interview with WIRED, neuroscientist Jay Neitz from the University of Washington describes chromatic bias as the way in which "[our] visual system is supposed to throw away information about the illuminant and extract information about the actual reflectance" - the illuminant being the background light, the reflectance being the light reflecting off the object. ${ }^{14}$ In the instance of the dress, the optical apparatus of observers are normal and well functioning. The discrepancy in perception is caused by differences in neural activity. If the brain can affect which colours we see in certain illuminating situations, it seems a small jump to the conclusion that the brain in general can affect which colours we see.

I will use one more example to help illustrate my point. People with chromesthesia, a subset of synesthesia, experience sensations of colour as a result of hearing certain sounds. As Jean-Pierre Ternaux explains in "Synesthesia: A Multimodal Combination of Senses," synesthesia in general occurs where "the excitation of one sense triggers stimulation in a completely different sensory modality." 15 This excitation occurs in the brain and can be considered "a fusion of sensory modalities, involving the specific cortical areas responsible for the sensations corresponding to the five "classical senses." "16 In layman's terms, the area of the brain responsible for one sense-experience gets mixed up with and stimulates another, though only the first has been directly stimulated by something in the outside world. Furthermore, Ternaux notes that "[recent] investigations using functional magnetic resonance imaging clearly indicated activation of the primary visual cortex in the absence of visual stimulation in a subject with colourword synesthesia." 17 For this subject, hearing certain words elicits

Dress," Wired, last modified February 26, 2015, accessed November 25

2018, www. wired.com/2015/02/science-one-agrees-colour-dress/.

14 Rogers, "The Science."

15 Jean-Pierre Ternaux, "Synesthesia: A Multimodal Combination of Senses," Leonardo 36, no. 4 (2003): 321.

16 Ternaux, "Synesthesia," 322.

17 Ternaux, "Synesthesia," 322 
experiences of colour, all without retinal stimulation. Thus, if experiences of colour can be conjured up in the brain-albeit via other sensory modalities - it seems reasonable to suggest that colour always arises in this way, though of course with the much-improved definition and vividness accompanying direct retinal stimulation.

\section{A POTENTIAL REBUTTAL}

Austin might respond to my challenge by arguing that I have not understood his view. In the case of a patient seeing pink rats, for example, Austin could maintain that the person is not so much perceiving some sort of conjured-up image of pink rats but rather that their mental state is simply such that they cannot tell the difference between seeing the floor and seeing pink rats. This seeing ("the patient ... sees pink rats") is not like normal seeing. ${ }^{18}$ Instead, the person believes they are seeing pink rats, without perceiving some image of them. This potential rebuttal plays off the other sort of delusion Austin describes - those of beliefs. I distinguished these from delusions of perception earlier because they seemed completely unrelated. But perhaps, just as delusions of grandeur or persecution are "primarily a matter of grossly disordered beliefs," so are delusions of perception..$^{19}$ If this is the case, the person's mind does not conjure up an image of pink rats, as there is no image to speak of. Instead, they simply believe they are having this experience.

This explanation solves nothing because there is no reason to believe one is seeing pink rats if one is not having an experience of them. Firstly, since pink rats do not exist, this experience cannot come from the external world. Secondly, someone who is not having an experience of pink rats would not say they are, and, if they did, they would simply be lying. Lies cannot account for all reported cases of delusion. Furthermore, while it is true that one can experience delusions of grandeur or of persecution without these convictions having any foundation in reality, delusions of perception are entirely different because they are perceived (in terms of sense-experience, whether real or conjured up by the mind). One does not have a delusion of grandeur in the same way one has a delusion of colour. Delusions of perception are not delusions of belief except in the sense that they may make one believe one sees something in the real world, when in fact it is conjured up in the mind.

\section{CONCLUSION}

Returning to colour, I conclude that because there is solid evidence to suggest our perception of colour heavily relies upon neural activity, such perception is conjured up in the mind and is thus a delusion. This leaves us with an uncomfortable decision to make: either colour perception is an outlier and all other aspects of normal perception (audition, olfaction, etc.) are direct, or else all perception is in some sense conjured up in the mind. The latter option seems the only acceptable one, on the assumption my premises are correct. If this is the case, direct perception is false. While this does not mean Ayer is correct (I have many qualms with sense-data theory as well), it does mean that Austin has no good way of distinguishing veridical from delusive perceptions or at least of distinguishing their causes. Of course, neither does Ayer, as all he can say is that they are both caused by sense-data, and this fails to be a very illuminating explanation at all. Thus, Ayer must fall back on the premises of sense-data theory, and Austin must reconsider his grounds for distinguishing perceptions of what is real from what is not. 

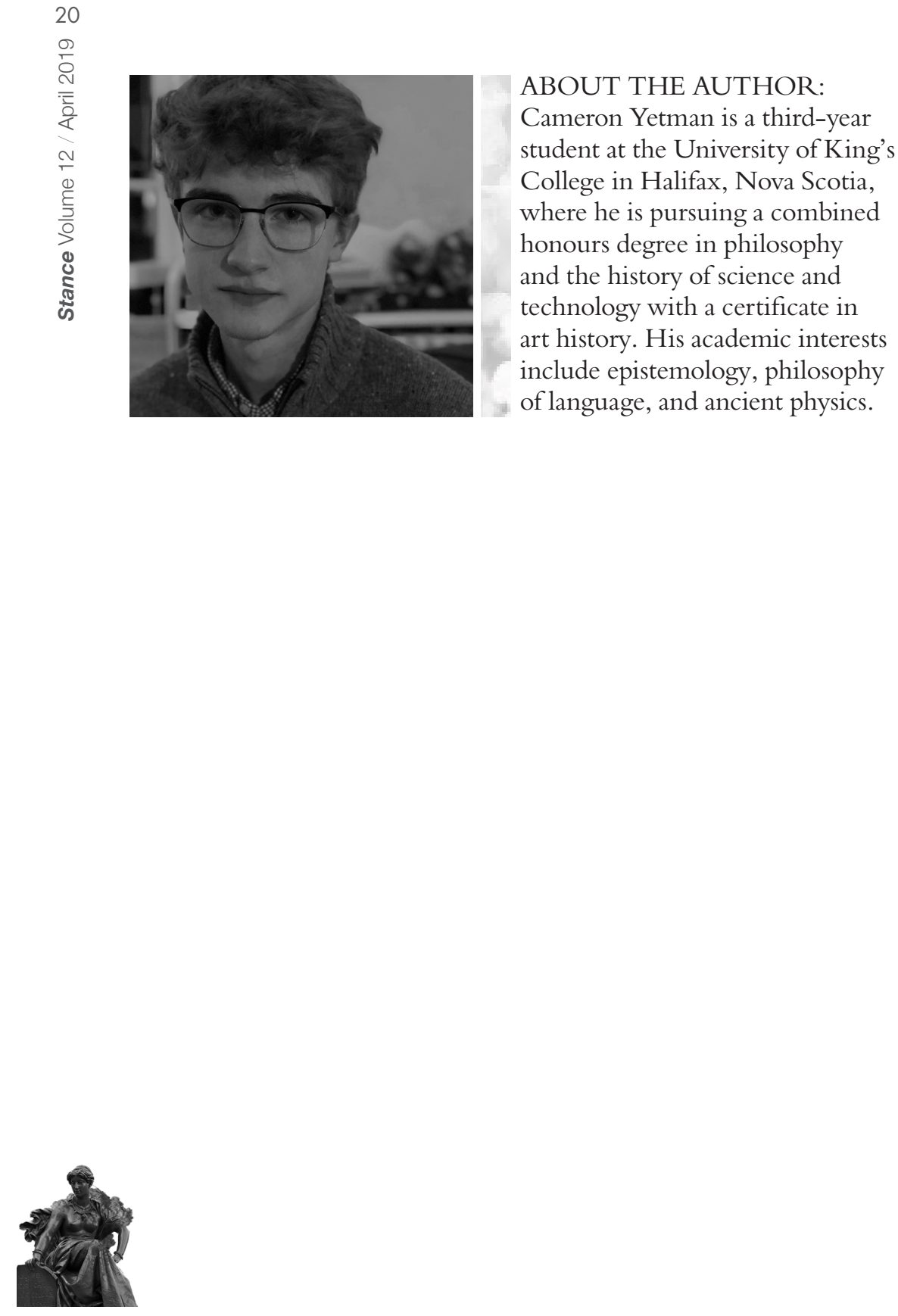